\title{
Herpes, Other Than Genital
}

National Cancer Institute

\section{Source}

National Cancer Institute. Herpes, Other Than Genital. NCI Thesaurus. Code C18834.

A funding category that should include all grants having to do with herpes research except those having to do with genital infection. 